\title{
The aggregation and sedimentation of nano-ZnO and nano-SiO2 in seawater
}

\author{
Ding Chen ${ }^{1, a}$ Airong Zheng ${ }^{2, b}$ Chunyu $\mathrm{Ma}^{3, \mathrm{c}}$ \\ ${ }^{1,2,3}$ College of Ocean and Earth Science, Xiamen University, Xiamen, China, 361005 \\ aemail, ${ }^{\text {bemail, }}{ }^{\mathrm{c} e m a i l,}$
}

Keywords: Zinc Oxide, Nano-Silica, Seawater, Reunion, Settlement

\begin{abstract}
With the development of nanoscience and nanotechnology industry, nanomaterials have gone into the natural water and it may have some impact ecosystems. This article intends to use nano-silica and zinc oxide different sizes with different concentrations of dispersed in filtered seawater to study the effect of these two nanomaterials agglomeration and sedimentation performance in seawater, to assess nanomaterials in the ocean environmental behavior reference. The results showed that these two nanomaterials, the same particle size, the higher the concentration, the greater the aggregate average particle size; the same concentration, the larger the particle size, the greater the average particle diameter of aggregates. With the particle size, the same concentration of nano- $\mathrm{ZnO}$ agglomeration is stronger than in seawater Nano $\mathrm{SiO} 2$. At $25{ }^{\circ} \mathrm{C} \sim$ $45{ }^{\circ} \mathrm{C}$, salinity of seawater 28.3 , the concentration of sedimentation rate $50 \mathrm{mg} / \mathrm{L}$ nano-SiO2 and nano-ZnO increases with increasing temperature. At $25{ }^{\circ} \mathrm{C}$, salinity of seawater 15.0 to 28.3 , the nano-SiO2 and nano-ZnO sedimentation rate solution with salinity increases. Under the same conditions, the nano-ZnO sedimentation rate in seawater nano $\mathrm{SiO} 2$.
\end{abstract}

\section{Introduction}

Nanotechnology research is within the range of scales $0.1 \mathrm{~nm} \sim 100 \mathrm{~nm}$ with special physical and chemical properties of the substance [1]. With the development of nanoscience and nanotechnology industry, various forms of nanomaterials through atmospheric deposition, transport of accidental spills, industrial and domestic waste water and the water cycle [2] and other ways to eventually enter aquatic ecosystems (such as rivers, lakes and oceans), enter these exogenous substances may have negative impacts on the latent normal ecosystem [3]. Therefore, it is necessary to fully understand the environmental behavior of nanomaterials in the water, and lay the foundation for the removal of contaminants nanoparticles.

Nanomaterials will soon gather in the solution, and the solution will vary but showing a different agglomeration effects [4-5]. Studies have revealed the aggregate effect of nanomaterials in some water environments [6-8], but their reunion is almost empty for research in the marine environment. Nanoparticles possible through its adsorption agglomeration or fused or conjugated to other marine environments particulate material, such that the particles and thus the settlement, and the move from the marine environment. Therefore, the study of nanomaterials reunion and settlement, awareness and understanding of the geochemical behavior of nanomaterials in the ocean has important significance.

According to Adams reported [9], artificial nano-silica and zinc oxide surface energy is large, prone to agglomeration, the agglomeration is closely related to the environmental conditions of natural water bodies. Water temperature, ionic strength and the presence of a surfactant will affect the physical and chemical properties of nano-silica and zinc oxide. According to Yue Feng Wei it reported that nano zinc oxide particles in an aqueous solution can only be a stable suspension of a few minutes [10]. According to a report Yuan laugh, agglomeration of nano titanium dioxide not only to change the flow of water, it is possible to change the settling characteristics of nanomaterials itself [7]. This article intends to nano-silica and zinc oxide different sizes with different concentrations of dispersed in filtered seawater to diameter of the nano material aggregates expressed its agglomeration, with its representation of its change in suspension turbidity in seawater 
settlement process to examine both nanomaterials agglomeration effect and sedimentation performance in seawater, providing a reference for assessing the environmental behavior of nanomaterials in the ocean.

\section{Materials and Methods}

Experimental Materials. Nanomaterials used in this experiment were $\mathrm{SiO} 2$ powder (particle diameter of $30 \mathrm{~nm}$ and $60 \mathrm{~nm}$, purity $>99.9 \%$ ) and $\mathrm{ZnO}$ powder (99.9\% particle size of 30nm and 90nm, purity>). Available from Hangzhou Wan Jing nano-materials Limited. Experiments with seawater from the ecological field Siming Xiamen University Campus of Ocean and Earth Institute, pH 8.0, salinity 28.3 , mixed fibers by $0.45 \mu$ m membrane filter.

The Reunion Experiment of Nanomaterials in Seawater. Unless otherwise indicated, the experiments were performed at room temperature of $24.5 \sim 25.0{ }^{\circ} \mathrm{C}$.

Weigh nano-silica $(30 \mathrm{~nm}, 60 \mathrm{~nm})$ and nano zinc oxide $(30 \mathrm{~nm}, 90 \mathrm{~nm}) 0.0020 \mathrm{~g}$ and $0.0050 \mathrm{~g}$ in $100 \mathrm{~mL}$ filter seawater to concentrations were $20 \mathrm{mg} / \mathrm{L}$ and $50 \mathrm{mg} / \mathrm{L}$. Determination of nanomaterials suspension was allowed to stand 3min by Malvern MS-2000 particle size analyzer at room temperature, $10 \mathrm{~min}, 5 \mathrm{~min}$, $20 \mathrm{~min}$ and $25 \mathrm{~min}$ after an average particle size of the aggregates.

The Deposition and Its Influencing Factors Experiment of Nanomaterials in Seawater. The nanomaterials silica and zinc oxide in seawater sedimentation experiments

WGZ-200 turbidity meter seawater at room temperature $25{ }^{\circ} \mathrm{C}$, measured under dark conditions nanomaterials concentration of 50mg / L (30nm-SiO2 and 30nm-ZnO) of $(\mathrm{S}=28.3)$ at different turbidity standing time until it So far no changes compared sedimentation rate of the two materials.

On the basis of experiments on concentration remains seawater salinity $(S=28.3)$ and nanomaterials (50mg/L) unchanged, change the temperature was $25{ }^{\circ} \mathrm{C}, 35{ }^{\circ} \mathrm{C}$ and $45{ }^{\circ} \mathrm{C}$, in a constant temperature water bath, at a different time to stand with WGZ-200 turbidity measuring turbidity in the dark, until no change so far to compare the influence of different temperatures on the sedimentation rate.

On the basis of experiments on maintaining the solution temperature $\left(25{ }^{\circ} \mathrm{C}\right)$ and concentration of nanomaterials (50mg / L) unchanged, with distilled seawater salinity changes were 28.3,21.2 and 15.0. Determination of turbidity in the dark and under static conditions, until it no longer changes so far to compare the influence of different salinity on the sedimentation rate.

Data Processing. Studies have shown that, under certain conditions, the settlement will make the nanoparticles in water turbidity of water dropping. The particle sedimentation and particle agglomeration ability related. Under normal circumstances, when a small water particles agglomerate into large particles, accelerated subsidence would decrease so that the water turbidity. In this study, the rate of sedimentation of nanoparticles with an approximate rate of change of turbidity that its calculation formula shown in Equation (1).

$$
\omega=\frac{T_{0}-T_{t}}{T_{0}} \times 100(1)
$$

Where, $\omega$ nanoparticles sedimentation rate (\%), $T_{t}-\mathrm{t}$ suspensions nanomaterials time turbidity (NTU), $T_{0}$ - initial moment nanomaterials suspension turbidity (NTU). 


\section{Results and Discussion}

Nano-Silica and Zinc Oxide Particles Agglomerate in Seawater.
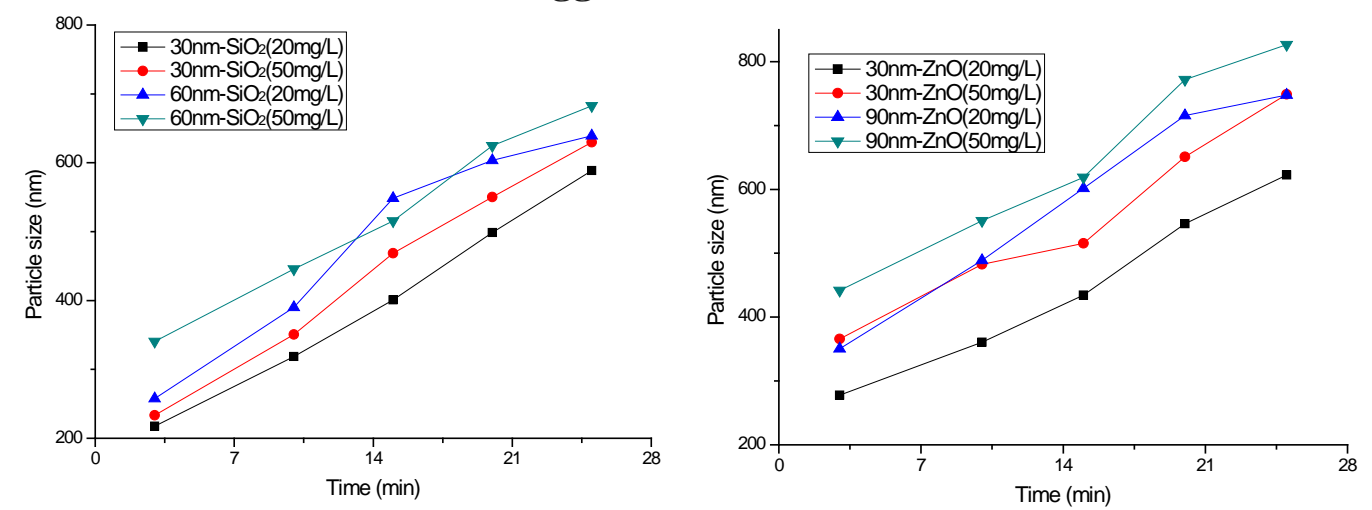

Figure 1 Change of the nano- $\mathrm{SiO}_{2}$ and nano-ZnO aggregation size with the standing time

Different concentrations of nanomaterials silica and zinc oxide suspension with an average particle size of aggregates standing time are shown in Figure 1. The figure shows that with the extension of the standing time, the average particle size of the nanoparticle aggregates gradually increased, and with remarkable standing time is proportional to the linear equations and correlation coefficients are shown in Table 1. Also apparent from Table 1, with the increase of nano-particle material (30nm and 60nm or 90nm), increasing concentrations (20mg / L and 50mg / L), its average particle size slope over time increases (except 60nm -SiO2 outside).

Table 1 Correlation between aggregation size of nano-particles and the standing time

\begin{tabular}{ccccc}
\hline Nanomaterials & $\begin{array}{c}\text { Concentration } \\
(\mathrm{mg} / \mathrm{L})\end{array}$ & Linear Equations (n=5) & $\mathrm{R}^{2}$ & $\mathrm{P}$ \\
\hline \multirow{2}{*}{$30 \mathrm{nmSiO}_{2}$} & 20 & $\mathrm{y}=17.001 \mathrm{x}+156.63$ & 0.9961 & $<0.01$ \\
& 50 & $\mathrm{y}=18.275 \mathrm{x}+179.14$ & 0.9952 & $<0.01$ \\
\multirow{2}{*}{$60 \mathrm{nmSiO}_{2}$} & 20 & $\mathrm{y}=18.218 \mathrm{x}+221.89$ & 0.9498 & $<0.01$ \\
& 50 & $\mathrm{y}=15.967 \mathrm{x}+228.25$ & 0.9936 & $<0.01$ \\
$30 \mathrm{nmZnO}$ & 20 & $\mathrm{y}=16.089 \mathrm{x}+213.42$ & 0.9868 & $<0.01$ \\
& 50 & $\mathrm{y}=17.204 \mathrm{x}+301.60$ & 0.9718 & $<0.01$ \\
$90 \mathrm{nmZnO}$ & 20 & $\mathrm{y}=18.977 \mathrm{x}+303.8$ & 0.9789 & $<0.01$ \\
& 50 & $\mathrm{y}=18.269 \mathrm{x}+375.23$ & 0.9788 & $<0.01$ \\
\hline
\end{tabular}

Experimental results show that seawater 30nm-SiO2 (20mg / L and 50mg / L), 60nm-SiO2 (20mg / L and 50mg / L) solution was allowed to stand for 25min average particle diameter of the aggregate average were $408.0 \mathrm{~nm}, 442.8 \mathrm{~nm}, 487.9 \mathrm{~nm}$ and $521.9 \mathrm{~nm}$; and average $30 \mathrm{~nm}-\mathrm{ZnO}(20 \mathrm{mg}$ / L and 50mg / L), 90nm-ZnO (20mg / L and 50mg / L) solution was allowed to stand for 25min average particle diameter of aggregates was $448.3 \mathrm{~nm}, 552.8 \mathrm{~nm}, 580.9 \mathrm{~nm}$ and $642.0 \mathrm{~nm}$, it can be seen on nano-silica and nano-ZnO two materials, the particle size at the same conditions, the higher the concentration, the greater the degree of agglomeration, particle aggregates diameter greater; and the same concentration, the larger the particle size, the average particle diameter of the aggregates becomes. At the same time, compared to the same diameter, the same concentration of aggregate average particle size of nano-SiO2 and $\mathrm{ZnO}$ data can be found, nano- $\mathrm{ZnO}$ agglomeration is stronger than in seawater Nano SiO2.

In this study, nano-zinc oxide and silicon dioxide in sea water can occur in varying degrees of agglomeration, the maximum average particle size of 500nm or more. The Yuan laugh a [7] The study showed that the concentration of the Pearl River in the raw water is $20 \mathrm{mg} / \mathrm{L}, 50 \mathrm{mg} / \mathrm{L}, 100$ $\mathrm{mg} / \mathrm{L}, 150 \mathrm{mg} / \mathrm{L}$ and $200 \mathrm{mg} / \mathrm{L}$ of TiO2 particles (monomers 100nm) They were gathered after 360 s became a diameter of $1426 \mathrm{~nm}, 1678 \mathrm{~nm}, 2169 \mathrm{~nm}, 2549 \mathrm{~nm}$ and $3696 \mathrm{~nm}$ of particles. There are also other studies have shown $[9,11]$, the particle size of nanomaterials in water far exceeds the data provided by the manufacturer, most of the nano particle size in the suspension of more than $100 \mathrm{~nm}$, the conventional micron-grade material similar. Thus, changes in the marine environment 
into the form of nanomaterials and properties, it is one of the aspects that must be considered when follow-up studies.

Settlement of Silicon Dioxide and Zinc Oxide Nanometer Particles in Seawater and Its Influencing Factors. Nanomaterials silicon dioxide and zinc oxide deposited in seawater

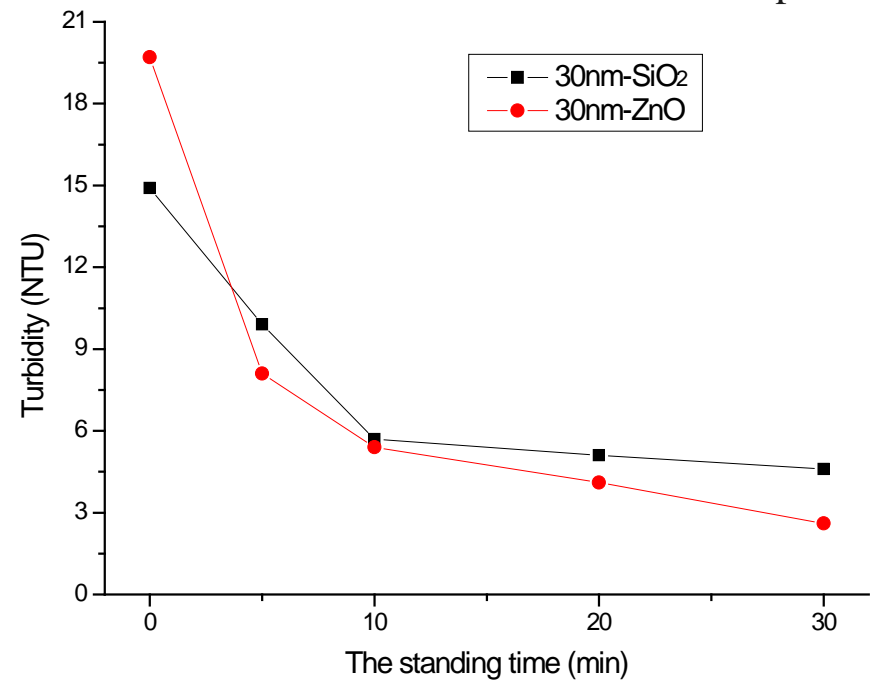

Figure 2 Change of the nano-materials' turbidity in the seawater with the standing time

Table 2 The sedimentation rate of nano-SiO2 and nano- $\mathrm{ZnO}$ in the seawater

\begin{tabular}{ccc}
\hline \multirow{2}{*}{ Standing time $(\min )$} & \multicolumn{2}{c}{ Sedimentation rate $(\%)$} \\
\cline { 2 - 3 } & $30 \mathrm{~nm}-\mathrm{SiO}_{2}$ & $30 \mathrm{~nm}-\mathrm{ZnO}$ \\
5 & 0.0 & 0.0 \\
10 & 33.6 & 58.8 \\
20 & 61.6 & 72.7 \\
30 & 65.9 & 79.0 \\
5min 30minThe average & 69.1 & 86.9 \\
sedimentation rate (\%) & 57.6 & 74.4 \\
\hline
\end{tabular}

Silica and zinc oxide nanomaterials turbidity and sedimentation rate in seawater is shown in Figure 2 and Table 2. Nano SiO2 initial solution turbidity was 14.9, 20min later reduced to 5.1, then stabilized unchanged; nano-ZnO initial turbidity was reduced to 2.6 after $19.7,30 \mathrm{~min}$. The figure shows, nano-silica suspension turbidity in 20min after stabilized, indicating a certain amount of nano-silica particles can be stably suspended in seawater; and nano-zinc oxide to stand in turbid waters within 30min degree will continue to decrease, indicating that the suspension is poor. In addition, $25{ }^{\circ} \mathrm{C}$ seawater nano-silica was allowed to stand $5 \mathrm{~min}$ to $30 \mathrm{~min}$, the settlement rate rose to $33.6 \%$ 69.1\%, while over the same period of Zinc Oxide by $58.8 \%$ settlement rate rose to $86.9 \%$, in each time test of nano $\mathrm{ZnO}$ nano-silica is greater than the rate of subsidence.

Silica and zinc oxide nanomaterials turbidity and sedimentation rate in seawater at different temperatures are shown in Figure 3. In the experimental temperature range $\left(25{ }^{\circ} \mathrm{C} \sim 45{ }^{\circ} \mathrm{C}\right.$ ) nano-silica suspension turbidity over time standing logarithmic decline, eventually stabilize, while standing with nano zinc oxide suspension turbidity time decreases exponentially. Its trend line equations and correlation coefficients are shown in Table 3. 

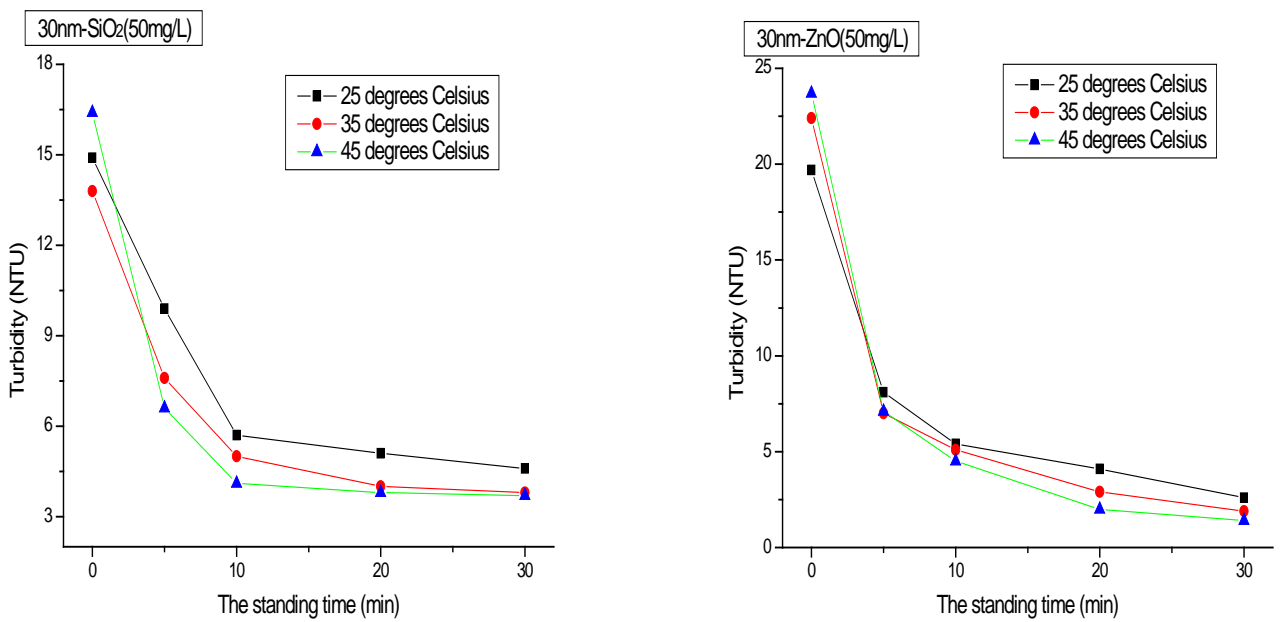

Figure 3 The curve of turbidity-time of nano- $\mathrm{SiO}_{2}$ and nano- $\mathrm{ZnO}$ in the seawater at different temperature

Table 3 Correlation between turbidity of nano-particles in the seawater at different temperature and the standing time

\begin{tabular}{ccccc}
\hline Nanomaterials & Temperature $\left({ }^{\circ} \mathrm{C}\right)$ & Curve equation $(\mathrm{n}=5)$ & $\mathrm{R}^{2}$ & $\mathrm{P}$ \\
\hline \multirow{3}{*}{$30 \mathrm{nmSiO}_{2}$} & 25 & $\mathrm{y}=-6.7433 \ln \mathrm{x}+14.497$ & 0.9606 & $<0.01$ \\
& 35 & $\mathrm{y}=-6.3909 \ln \mathrm{x}+15.027$ & 0.9465 & $<0.01$ \\
& 45 & $\mathrm{y}=-7.9403 \ln \mathrm{x}+14.523$ & 0.8630 & $<0.01$ \\
$30 \mathrm{nmZnO}$ & 25 & $\mathrm{y}=25.64 \mathrm{e}^{-0.4731 \mathrm{x}}$ & 0.9511 & $<0.01$ \\
& 35 & $\mathrm{y}=30.65 \mathrm{e}^{-0.5816 \mathrm{x}}$ & 0.9469 & $<0.01$ \\
& 45 & $\mathrm{y}=36.94 \mathrm{e}^{-0.6925 \mathrm{x}}$ & 0.9619 & $<0.01$ \\
\hline
\end{tabular}

At $25{ }^{\circ} \mathrm{C}, 35{ }^{\circ} \mathrm{C}$ and $45{ }^{\circ} \mathrm{C}$, nano-SiO2 initial solution turbidity respectively $14.9,13.8$ and 16.4,20min later reduced to 5.1,4.0 and 3.8, and thereafter stabilized unchanged; nano-ZnO initial turbidity is as 19.7,22.4 and 23.7,30min after reduced 2.6,1.9 and 1.4. Can also be seen from Table 3 , the average settlement rate of nano-silica in $5 \mathrm{~min} \sim 30 \mathrm{~min}$ at $25{ }^{\circ} \mathrm{C}, 57.6 \%$, respectively at $35{ }^{\circ} \mathrm{C}$ and $45{ }^{\circ} \mathrm{C}, 63.4 \%$ and $72.4 \%$, Zinc Oxide at the same temperature the average sedimentation rate was $74.4 \%, 81.2 \%$ and $84.0 \%$, respectively. Silica and zinc oxide nano-materials less likely to move out in the cold sea water, which is a laugh [7] study done in fresh water and Yuan, that is, the lower the Pearl River raw water temperature, TiO2 particles settle more incomplete conclusions unanimously. Seen after nanomaterials enter the water, the impact on the body of water caused by low temperature is greater.
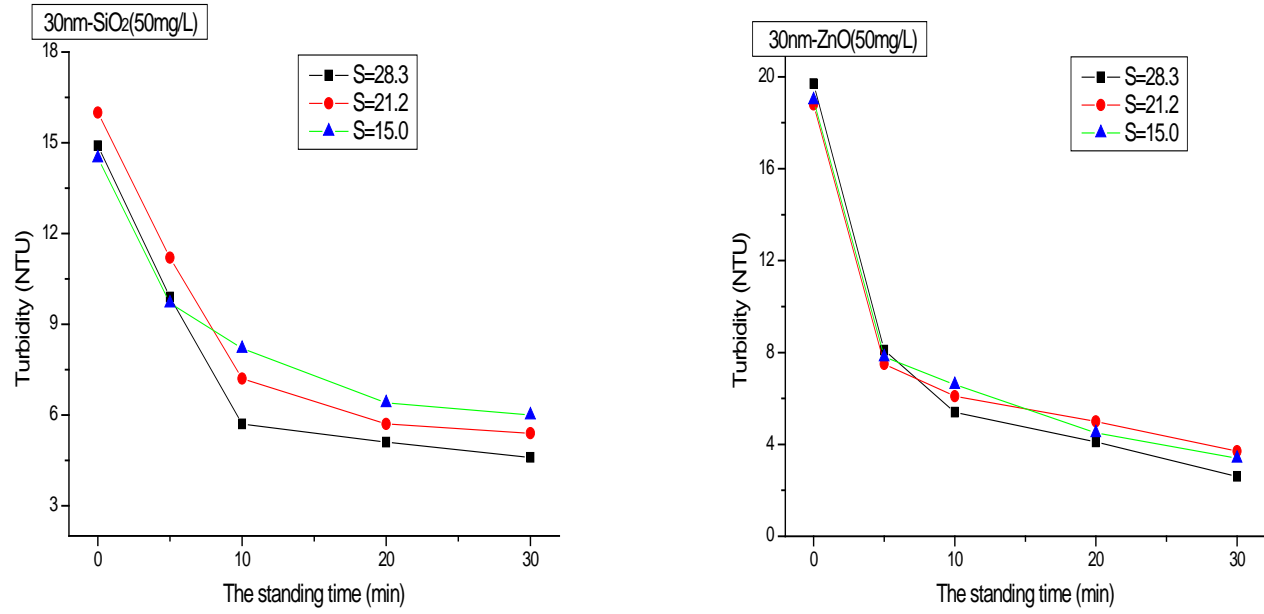

Figure 4 The curve of turbidity-time of nano-SiO${ }_{2}$ and nano- $\mathrm{ZnO}$ in the seawater at different salinity 
Silica and zinc oxide nanomaterials turbidity and sedimentation rates in different salinity in Figure 4. It is seen in the experimental salinity range (15.0 to 28.3) nano-silica suspension turbidity over time standing logarithmic decline, eventually stabilized, and nano zinc oxide suspension turbidity exponentially decline. Its trend line equations and correlation coefficients are shown in Table 4.

Table 4 Correlation between turbidity of nano-particles in the seawater at different salinity and the standing time

\begin{tabular}{ccccc}
\hline Nanomaterials & Salinity & Curve equation $(\mathrm{n}=5)$ & $\mathrm{R}^{2}$ & $\mathrm{P}$ \\
\hline \multirow{3}{*}{$30 \mathrm{nmSiO}_{2}$} & 28.3 & $\mathrm{y}=-6.7433 \ln \mathrm{x}+14.497$ & 0.9606 & $<0.01$ \\
& 21.2 & $\mathrm{y}=-6.9948 \ln \mathrm{x}+15.798$ & 0.9773 & $<0.01$ \\
& 15.0 & $\mathrm{y}=-5.3450 \ln \mathrm{x}+14.078$ & 0.9792 & $<0.01$ \\
\multirow{3}{*}{$30 \mathrm{nmZnO}$} & 28.3 & $\mathrm{y}=25.64 \mathrm{e}^{-0.4731 \mathrm{x}}$ & 0.9511 & $<0.01$ \\
& 21.2 & $\mathrm{y}=20.80 \mathrm{e}^{-0.3673 \mathrm{x}}$ & 0.8822 & $<0.01$ \\
& 15.0 & $\mathrm{y}=22.65 \mathrm{e}^{-0.3991 x}$ & 0.9229 & $<0.01$ \\
\hline
\end{tabular}

In the salinity of seawater28.3, 21.2 and 15.0, the initial turbidity nano-SiO2 were 14.9, 16.0 and 14.5, 20min after reduced 5.1, 5.7 and 6.4. The initial turbidity of nano ZnO was 19.7, 18.8 and 19.0, 30min after reduced 2.6, 3.7 and 3.4. Table 4 shows that, in the salinity of seawater 28.3,21.2 and 15.0 nano-silica average sedimentation rate in $5 \mathrm{~min} \sim 30 \mathrm{~min}$ is respectively $57.6 \%, 54.0 \%$ and $47.8 \%$, while in the same period the average Zinc Oxide sedimentation rates were $74.4 \%, 70.5 \%$ and $70.6 \%$, respectively. Both with decreasing salinity have decreased. The reason is that when the salinity increased ionic strength increases, the compression of the electrical double layer of silicon dioxide and zinc oxide nano-particle surface, reducing the repulsion between nanoparticles [12-13], in favor of nanoparticles agglomeration, thereby increasing the sedimentation rate of the particles. This indicates that nanomaterials silica and zinc oxide in low-salinity seawater easy settlement, which is not easy to move from the sea.

\section{Conclusion}

Results of the agglomeration experiments indicate nanomaterials: particle size 30nm and 60nm, average particle diameter of aggregate concentration of $20 \sim 50 \mathrm{mg} / \mathrm{L}$ of $\mathrm{SiO} 2$ is formed in $25 \mathrm{~min}$ at between $408.0 \sim 521.9 \mathrm{~nm}$; particle size $30 \mathrm{~nm}$ and $90 \mathrm{~nm}$, the average particle size aggregate the same concentration of $\mathrm{ZnO}$ is formed at the same time in between $448.3 \sim 642.0 \mathrm{~nm}$. For every two kinds of nano materials, the particle size is the same, the higher the concentration, the greater the aggregate average particle size; the same concentration, the larger the particle size, the greater the average particle diameter of aggregates. With the particle size, the same concentration of nano-ZnO agglomeration is stronger than in seawater Nano SiO2.

The settlement results nanomaterials show: at $25{ }^{\circ} \mathrm{C} \sim 45{ }^{\circ} \mathrm{C}$, salinity of seawater 28.3 , the concentration of sedimentation rate $50 \mathrm{mg} / \mathrm{L}$ nano-SiO2 and nano-ZnO increases with increasing temperature. At $25{ }^{\circ} \mathrm{C}$, salinity of seawater 15.0 to 28.3 , the nano-SiO2 and nano-ZnO sedimentation rate solution with salinity increases. Under the same conditions, the nano-ZnO sedimentation rate in seawater nano $\mathrm{SiO} 2$.

\section{References}

[1] Huang Dehuan. Nanotechnology and Applications, Vol. 6 (2001) No 53, p.25-26

[2] Ju-Nam Y, Lead J R. Sci Total Environ, Vol. 12 (2008) No 400, p.396-414

[3] Daughton CG. Environmental Impact Assessment Review, Vol.24 (2004) No 19, p.711-732

[4] Gurr JR, Wang AS, Chen CH,et al.. Toxicology, Vol. 29 (2005) No 27, p.66-73

[5] Jin CY, Zhu BS, Wang XF, et al. Chem Res Toxicol, Vol. 8 (2008) No 27, p. 1871-1877

[6] Long T C, Sale H N, Tilton R D, et al. Environ. Sci. Technol, Vol. 4 (2006) No 27, p. 27-33

[7] Yuan Xiaoyi, Zhou Qin. Guangdong Technology University, Vol. 3 (2005) No 22, p.17-20 
[8] Du Hairong, Zhu Zhongping. Environment and Health, Vol. 7 (2012) No29, p. 617-619

[9] Adams L K, Lyon D Y, Alvarezp J J Water Research, Vol.19 (2006) No 40, p. 3527-3532

[10] Feng Weiyue, Wang Hiafang. Science Press, Vol. 29 (2010) No 27, p.66-73

[11] Xiong DAaowen, Li Zheng, Fang Tao. Environmental Pollution and Control, Vol. 4 (2009) No 27, p. 71-77

[12] Zhu Yanping. Tianjin Medical University, Vol. 2 (2005) No 11, p. 338-341

[13] Li Qiang, Gao Lian, Luan Weiling Journal of Inorganic Materials, Vol.14 (1999) No 40, p.813 